\section{The American Association for Thoracic Surgery}

\section{Editor Search Announcement}

The distinguished position of Editor of The Journal of Thoracic and Cardiovascular Surgery will become available when Dr Lawrence H. Cohn completes his term December 31, 2014. The Publications Committee of the American Association for Thoracic Surgery is initiating a broad-based search for a successor with an established reputation in cardiothoracic surgery, a history of high-quality scholarship, and an exciting vision for the future of our flagship journal. The application process is now open and will close on $\mathrm{Au}-$ gust 30th of this year. Interviews will take place in the latter half of 2013 and the Council will present its recommendation for Editor-elect to the membership for their consideration at the 2014 Executive session. All Active and Senior Members are strongly encouraged to consider pursuing this important position. Interested applicants should contact Ryan Walther at the editorial offices of the Journal at (978) 927-8330 or rwalther@aats.org for position description and application information.

\section{AATS/ACCF Heart Valve Summit 2013: Medical, Surgical, and Interventional Decision Making}

September 26-28, 2013

Chicago Marriott Downtown Magnificent Mile

Chicago, IL, USA

\section{Sessions Include:}

Basics of Aortic Stenosis

New Treatment Approaches

Tough Issues in AS Management

The Intermediate (and Low-Risk) Patient

Mitral Regurgitation: Anatomy, Imaging, Decision Making

Mitral Valve Regurgitation in Heart Failure

Complications Associated With Mitral Valve Disease:

Real Cases

HOCM and Mitral Regurgitation

Tricuspid Valve Disease

Failed Mitral Valve Surgery

Valvular Heart Disease: The Future

Management Challenges in Valve Disease

\section{Honored Lecturers:}

Tirone E. David, MD, FRCS, "Reconstructive Valve Surgery-A Career of Learning"

Rick Nishimura, MD, FACC, "Challenges in Guidelines

Development for Valvular Heart Disease"

View the Full Program, Register, and Reserve Housing at www.aats.org/valve

\section{AATS Focus on Thoracic Surgery: Esophageal Disease}

November 15-16, 2013

Boston Marriott Copley Place

Boston, MA, USA

\section{Program Directors:}

G. Alec Patterson, MD

David J. Sugarbaker, MD

\section{Program Committee:}

Thomas A. D'Amico, MD

Shaf Keshavjee, MD

James D. Luketich, MD

Bryan F. Meyers, MD, MPH

Scott J. Swanson, MD

Session Highlights:

Esophageal Physiology Testing and GERD

Motor Disorders of the Esophagus

Paraesophageal Hernia

Potpourri of Benign Topics

Understating Esophageal Cancer

The Best Esophagectomy

Challenging Technical Aspects of the Esophagectomy

View full program and register for the meeting at http:// aats.org/esophageal/

\section{AATS Awards Applications}

Now Available at www.aats.org

AATS Critical Care Scholarship provides an opportunity for cardiothoracic surgery residents to attend the 2013 CVT Critical Care conference on October 10-12, 2013, in Washington, DC

- Residents must be attending an ACGME accredited cardiothoracic surgical training program in the United States or RCPSC accredited cardiothoracic surgical residency program in Canada.

- The AATS will provide a stipend of $\$ 500$ to the resident's institution to help offset the cost of travel and hotel accommodations.

- Recipients will received complimentary registration to the Critical Care Conference.

- Participation is limited to one resident per institution and up to 75 recipients will be selected for this award on a first come first served basis.

Deadline: August 30, 2013 